

Original article

\title{
Comparative Study Between Intramedullary K-wire Fixation Versus Transverse Pinning in Treatment of Fifth Metacarpal Neck Fracture
}

\author{
Ismaeel Shaker Eraky Sallam [a]; Ashraf Eltabie Ezzeldeen [b]; Samir Ahmed El-Shoura ${ }^{[b]}$
}

Department of Orthopedic Surgery, Nasser General Hospital, Ministry of Health, Egypt [a]

Department of Orthopedic Surgery, Damietta Faculty of Medicine, Al-Azhar University, Egypt $\left.{ }^{[\mathrm{b}}\right]$

Corresponding author

Ismaeel Shaker Eraky Sallam

Email: ises.ortho@domazhermedicine.edu.eg

Received at: June 07, 2020; Revised at: July 18, 2020; Accepted at: July 18, 2020; Available online at: July 18, 2020

DOI: 10.21608/ijma.2020.32039.1134

\section{ABSTRACT}

Background: Fifth metacarpals and phalangeal fractures are common, and neck fractures of the fifth metacarpal is the commonest. Improper treatment is associated with negative economic impact due to its associated disabilities.

Aim of the work: To compare between intra-medullary and transvers K-wires for fifth metacarpal neck fractures.

Patients and Methods: Thirty patients with $5^{\text {th }}$ metacarpal neck fracture were included. Fifteen treated by intramedullary k-wire fixation, and fifteen treated by transverse k-wire pinning. Preoperatively, patients were evaluated by clinical, radiological and laboratory studies. Postoperatively, they were assessed clinically and by imaging studies. Objective assessment had been achieved by the total active range of motion [TAM] and hand-grip strength.

Results: Both groups were comparable as regard to patient and injury characteristics. Punch was the most common mechanism of injury. The right side was affected in $80 \%$, and the transverse fracture was the most common [reported in $53.3 \%$ ]. Finally, outcome was slightly better in group 1, except for one patient of non-union. The results based on TAM $\%$ were excellent, good, fair and poor among $60.0 \%, 26.7 \%, 6.7 \%$ and $6.7 \%$ in group 1 , compared to $83.3 \%, 40.0 \%$, $0.0 \%$ and $6.7 \%$ in group 2 with the same order. The time to union ranged between 6 and 14 weeks. Finally, complications were reported in $20 \%$ of group 1 and $33.3 \%$ of group 2 .

Conclusion: Intramedullary K-wire Fixation and Transverse Pinning provide an optimal treatment options for Fifth Metacarpal Neck Fracture. Intramedullary K-wire Fixation provide slightly better outcome. However, the superiority is not statistically significant.

Keywords: Fifth metacarpal; K-wire; Intramedullary; Pinning; Fracture.

This is an open access article under the Creative Commons license [CC BY] [https://creativecommons.org/licenses/by/2.0/]

Please cite this article as: Sallam ISE, Ezzeldeen AE, El-Shoura SA. Comparative Study Between Intramedullary K-wire Fixation Versus Transverse Pinning in Treatment of Fifth Metacarpal Neck Fracture. IJMA 2020; 2[3]: 580-589.

\footnotetext{
* Main subject and any subcategories have been classified according to the research topic.
} 


\section{INTRODUCTION}

The hand is precious to everybody as the human hand performs countless acts from simple grasp to complex skills[1]. Fractures of the metacarpals and phalanges are the most common fractures in the upper extremity; it is commonest in young active males and peaks between ages 10 and 40 years ${ }^{[2]}$.

The $5^{\text {th }}$ metacarpal fractures accounts for $40 \%$ of all hand fractures. Neck fracture are the commonest, as it is the weakest point in metacarpals, and accounts for about $10 \%$ of all hand fractures. Improper management of hand fractures has negative economic effect due to disabilities that occur to hands of workers, athletes and housewives ${ }^{[3]}$.

Fractures of the fifth metacarpal bone neck usually occur as a result of punching or in a fall, hence the name "boxer's fracture". This injury has been described as a tolerable fracture in an intolerable patient[4].

Various techniques have been applied for the operative treatment of metacarpal fractures as interfragmentary screws, plate and screws, external fixator, intramedullary or transverse Kirschner wires [K-wires], cerclage, intra-osseous wiring and tension band wiring. Regardless of the method of treatment, the goal is full and rapid restoration of hand function ${ }^{[5]}$.

Kirschner wires have been used for fixation of metacarpal fractures many years ago and still considered one of the best methods for fixation of metacarpal fractures [6].

Foucher ${ }^{[7]}$ advocated the use of intramedullary wires while Berkman and Miles [8] described the use of transverse pinning method where wires are passed transversely between the 5 th and the $4^{\text {th }}$ metacarpal bones. Both methods were discussed in literature with minimal disadvantages.

It is important to ensure early and near immediate postoperative hand movement to improve the functional outcome and avoid joint stiffness which may occur even if there are no intra-articular fractures due to delay in starting active motion [9]. As different techniques were described, the need to decide the ideal treatment method is crucial. Here, we try to explore which K-wire is better, intramedullary or transverse type.

\section{AIM OF THE WORK}

This study was planned to compare between two common methods for fixation of $5^{\text {th }}$ metacarpal neck fractures: intra-medullary K-wires vs transvers Kwires to evaluate the advantage and disadvantage of each technique and to assess the results.

\section{PATIENTS AND METHODS}

Between October 2018 and August 2019, thirty patients [a convenient sample] with $5^{\text {th }}$ metacarpal neck fracture underwent closed reduction internal fixation. Fifteen of them were treated by intramedullary k-wire fixation method [Group 1], while the other fifteen were treated by transverse kwire pinning method [Group 2]. The classification of patients had been carried out randomly [closed envelop technique]. The postoperative follow-up ranged between 3 and 4 months.

The inclusion criteria were: closed fracture, minimal soft tissue injury, moderate to severe angulation $\left[>30^{\circ}\right]$, and failed non-operative treatment. On the other side, exclusion criteria were: extremes of age [ $>65$ or $<15$ years old], open fractures, comminuted fractures, intra-articular fractures, and patients with bad general conditions.

Preoperative evaluation consisted of full history interrogation, time passed since injury to surgical intervention, injury characteristics, clinical examination [swelling and/or deformity, skin and soft tissues and neurovascular assessment]. Furthermore, all patients were assessed by required Lab and radiological investigations. Preoperative investigations included complete blood count [CBC], coagulation profile, liver \& kidney function tests, blood glucose, hepatitis markers and human immunodeficiency virus [HIV] test]. Radiological evaluation consisted of X-ray of the affected hand anterior-posterior [AP] and oblique views to assess type of fracture.

Ethical considerations: The study protocol was approved by the local institutional research and ethics committee [IRP-number; IRB00012367 [1810-001], and an informed consent was obtained from each patient before participation in the study. All were assured about their confidentiality and their rights to withdraw at any time was guaranteed [fortunately, none of them asked to withdraw]. Other ethical codes were applied according to declaration of Helsinki. 


\section{Surgical procedures:}

The patients had been placed in supine position with hand on a side hand table or directly on fluoroscopic device [C-arm]. The majority of patients had been operated under general anesthesia [14 patients in each group, and one patient in each group underwent regional anesthesia [axillary brachial plexus block]].

Preparation and draping: Both ventral and dorsal sides of the hand and forearm had been scrubbed by antiseptic solutions, a sterile drape sheet had been placed on the side table or the fluoroscopic device and a combination of sterile towels and sheets had been applied leaving exposed only the hand and distal forearm.

Percutaneous intramedullary pinning technique[10]: The metacarpophalangeal joint had been flexed to obtain control of the distal fragment. Under fluoroscopic control, a smooth $\mathrm{K}$ wire of $1 \mathrm{~mm}$ or $1.25 \mathrm{~mm}$ had been inserted by hand on the radial or ulnar collateral recess, proximal to the fracture site in antegrade manner and distal to the fracture site in retrograde technique. Antegrade technique had been completed for 10 patients, while retrograde technique had been completed for 5 patients. An oblique or near true lateral $x$-ray view had been done to confirm placement of the pin in the sagittal plane. The wire had been then advanced using power drill into the intramedullary canal of the metacarpal bone passing the fracture site to be seated in the other end of the bone. A second wire had been passed through the other collateral recess, this had been used to complete the fracture stabilization and to prevent rotation of the fracture. The wires and reduction had been checked by fluoroscope in both AP and oblique views [Figure 1] After that, the K-wires had been bent and kept out to be removed later. The patients' hands had been kept in an extended below-elbow dorsal splint in functional position.

Percutaneous transverse pinning technique[11]: The displaced fifth metacarpal neck fracture had been reduced by traction and reduction. Under fluoroscopic control, smooth K-wire had been inserted on the medial cortex of the metacarpal bone proximal to fracture after pushing abductor digiti minimi muscle palmar-ward to prevent impaction of the muscle. K-wire fixed the fifth metacarpal to the fourth metacarpal by transverse K-wire crossing four cortices [two cortices of $5^{\text {th }}$ metacarpal and two cortices of $4^{\text {th }}$ metacarpal]. A second transverse Kwire had been passed distal to fracture site and may be more than two K-wires according to stabilization of the reduction. The wires and reduction had been checked by fluoroscope in both positions AP and oblique [Figure 2]. After that, the K-wires had been bent and kept out to be removed later. The patients' hands had been kept in an extended below-elbow dorsal splint in functional position.

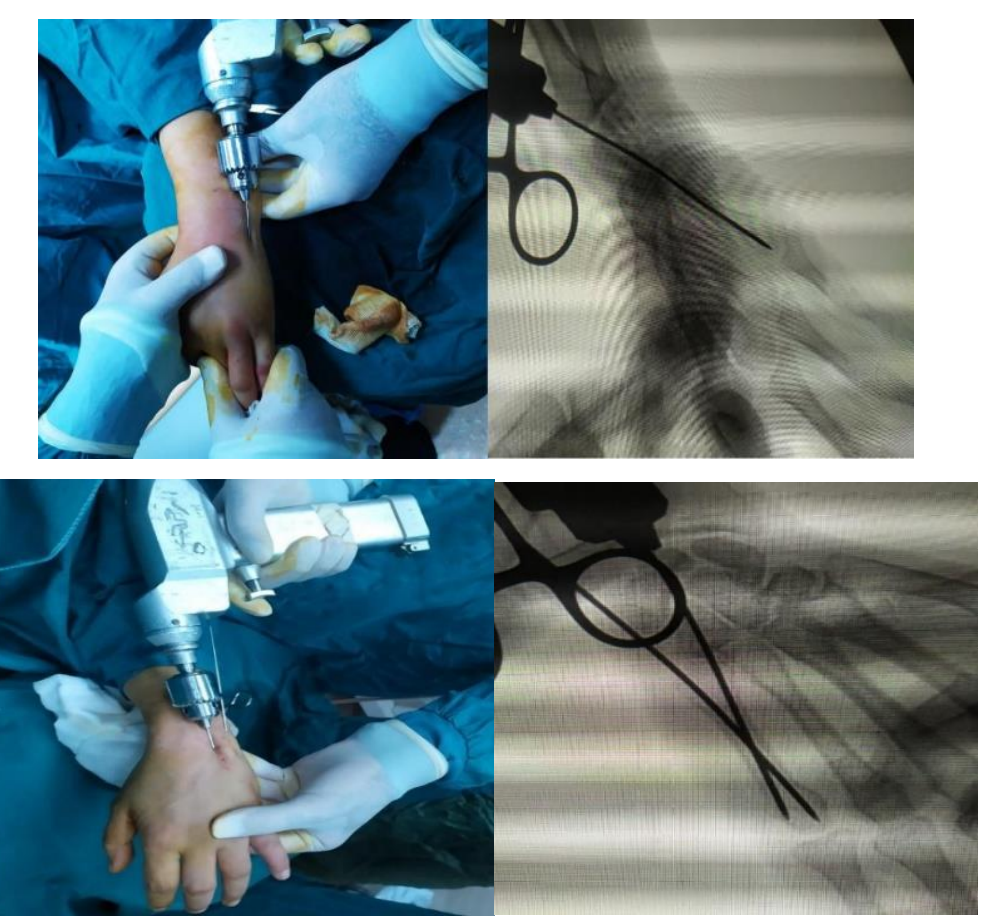

Figure [1]: Steps of intramedullary k-wire technique 


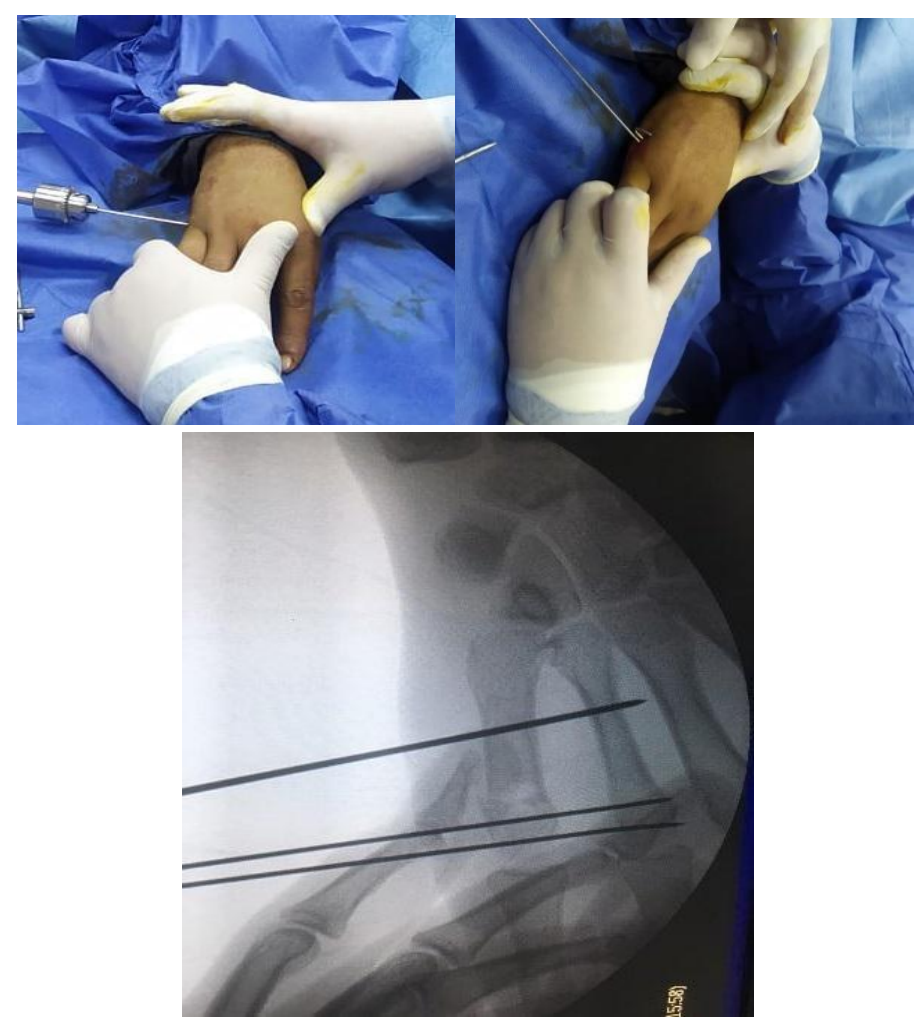

Figure [2]: Steps of transverse k-wire technique

Follow up: After either of the two techniques, a plaster splint had been applied postoperatively with the wrist in functional position including the wrist and fingers. It consisted of dorsiflexion of the wrist between 20 and 35 degree and flexion of the metacarpophalangeal [MCP] and proximal interphalangeal [PIP] joints between 45 and 60 degrees for 3 or 4 weeks. The hand had been kept elevated until edema resolved. An $\mathrm{x}$ ray had been carried out immediately postoperative, and serial $x$ rays had been done every 3 weeks to assess degree of union. Active motion of the entire hand had been encouraged as soon as the postoperative splint had been removed after 3 to 4 weeks. After that, the use of the injured hand in activities of daily living had been encouraged within the limits of pain. Heavy work had been avoided until progress towards union became sufficient by radiological evaluation.

Objective assessment included assessed of active range of motion and hand-grip strength. Range of active motion in each joint of the affected finger had been evaluated according to total active motion [TAM] score. TAM had been calculated 12 weeks after the surgical intervention. TAM had been described as the sum of active motion of MPJ, PIPJ and DIPJ of an individual digit and this calculation had been compared with the same digit in the contralateral hand.

How TAM score had been calculated? ${ }^{[12]}$ Patient's flexion and extension of the MPJ, PIPJ and DIPJ of a finger had been evaluated. The values had been measured by a goniometer. TAM score had been calculated by subtracting the total active flexion of the MPJ, PIPJ and DIPJ from the total extension deficit of the same joints. The same steps had been repeated for the corresponding joints of the contralateral hand. TAM \% had been calculated by dividing TAM of the affected finger by the TAM of the contralateral one. The results were considered excelled if TAM score $\left[250^{\circ}-260^{\circ}\right]$, good if TAM score $\left[210^{\circ}-249^{\circ}\right]$, fair if TAM score $\left[180^{\circ}-209^{\circ}\right]$, poor if TAM score $\left[<180^{\circ}\right]$

Hand grip strength $\left[{ }^{[13]}\right.$ : It had been measured by sphygmomanometer. First, the sphygmomanometer had been rolled into cylinder comfortable for the patient to grip at rest. The cuff had been inflated to $20 \mathrm{mmHg}$. The patient had been asked to apply maximal grip force to the cuff. The gauge needle indicates the patient's applied pressure [figure 3]. 

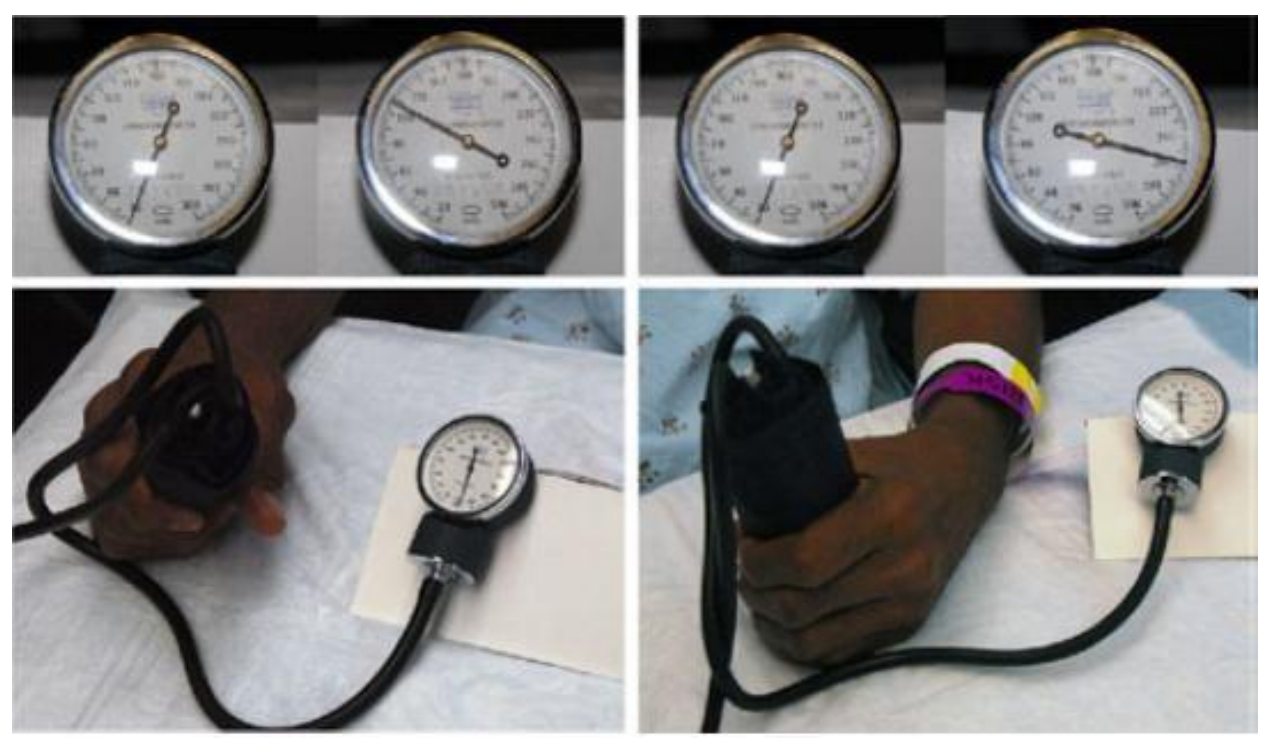

Figure [3]: Hand grip strength measuring

Data analysis: The collected data were fed to an excel sheet, coded and analyzed by statistical package for social science [SPSS], version 20 [IBM corporation, USA, Chicago]. Data were presented as mean $\pm S D$ if they were numerical and as number [frequency] and percentage if they were categorical. Groups were compared by appropriate statistical tests [Independent samples student [t] test, Chi square, and Mann-Whitney [U] tests according to type of data]. The accepted error was set at 0.05, and considered as the cutoff for significance.

\section{RESULTS}

All of the 30 patients included in this study had a follow up ranging from 3 to 6 months. Objective assessment of the final postoperative condition was done for all the patients. Group 1 included those treatment by intramedullary k-wire fixation method [15 subject], while group 2 included those treated by transverse k-wire pinning method [15 subjects].

Patient characteristics were presented in table [1], and both groups were comparable as regard to patient age, gender and occupation, with males and manual workers represents the majority in both groups [males represented $86.7 \%$ of group 1 and $80.0 \%$ of group 2, while manual workers represented $66.7 \%$ and $46.7 \%$ of groups 1 and 2 respectively].

Regarding injury characteristics, both groups were comparable as regard to mechanism of injury, time from injury to intervention, association injuries, the affected side and type of fracture. Punch was the most common mechanism of injury [reported in $73.3 \%$ and $53.3 \%$ of groups 1 and 2 respectively]. The time from injury to intervention ranged between 1 to 21 days. Associated injury reported in 2 patients in each group. The right side was affected in $80 \%$ of each group, and the transverse fracture was the most common [reported in $53.3 \%$ of each group], and intra-articular fracture was reported in only one patient in the second group [Detailed results are depicted in table 2].

Postoperative assessment revealed nonsignificant difference between both groups. TAM score ranged between 170 and 260, with slight increase in group 1. The results based on TAM $\%$ was excellent, good, fair and poor among $60.0 \%$, $26.7 \%, 6.7 \%$ and $6.7 \%$ in group 1 respectively, compared to $83.3 \%, 40.0 \%, 0.0 \%$ and $6.7 \%$ in group 2 with the same order. Hand grip strength ranged between 70 and $100 \mathrm{mmHg}$ with slight increase in group 1 when compared to group 2 $[92.00 \pm 8.61$ vs $88.67 \pm 8.33$ respectively]. The time to union ranged between 6 and 14 weeks with minimal decrease in group 1. Finally, complications were reported in $20 \%$ of group 1 and $33.3 \%$ of group 2. All were mild and treated conservatively except one patient of non-union in group 1. The majority of complications were in the form of pin site infection [13.3\% of group 1 and $26.7 \%$ of group 2] [Table 3]. 
Table [1]: Patient characteristics

\begin{tabular}{|l|l|c|c|c|c|}
\hline \multicolumn{2}{|c|}{ Variables } & Group 1 & Group 2 & Test & P value \\
\hline \multirow{2}{*}{ Age } & $\begin{array}{c}32.73 \pm 13.80 ; \\
19-60\end{array}$ & $\begin{array}{c}32.66 \pm 13.33 ; \\
17-61\end{array}$ & 0.013 & 0.98 \\
\hline \multirow{3}{*}{ Gender } & Male & $13[86.7 \%]$ & $12[80.0 \%]$ & \multirow{2}{*}{0.24} & 0.62 \\
\cline { 2 - 4 } & Female & $2[13.3 \%]$ & $3[20.0 \%]$ & & \multirow{2}{*}{2.31} \\
\hline \multirow{3}{*}{ Occupation } & Manual & $10[66.7 \%]$ & $7[46.7 \%]$ & & \\
\cline { 2 - 4 } & Office & $1[6.7 \%]$ & $4[26.7 \%]$ & & \\
\cline { 2 - 4 } & Student & $1[6.7 \%]$ & $1[6.7 \%]$ & & \\
\cline { 2 - 4 } & No & $3[20.0 \%]$ & $3[20.0 \%]$ & & \\
\end{tabular}

Table [2]: Injury characteristics among studied populations

\begin{tabular}{|c|c|c|c|c|c|}
\hline \multicolumn{2}{|c|}{ Variables } & Group 1 & Group 2 & Test & $P$ value \\
\hline \multirow[t]{4}{*}{ Mechanism of injury } & Punch & $11[73.3 \%]$ & $8[53.3 \%]$ & \multirow[t]{4}{*}{1.95} & \multirow[t]{4}{*}{0.58} \\
\hline & Fall & $3[20.0 \%]$ & $4[26.7 \%]$ & & \\
\hline & RTA & $1[6.7 \%]$ & $2[13.3 \%]$ & & \\
\hline & Direct & $0[0.0 \%]$ & $1[6.7 \%]$ & & \\
\hline \multicolumn{2}{|c|}{ Time from injury to intervention [days] } & $\begin{array}{c}9.93 \pm 3.61 \\
2-15\end{array}$ & $\begin{array}{c}9.0 \pm 5.74 \\
1-21\end{array}$ & 0.53 & 0.60 \\
\hline \multicolumn{2}{|l|}{ Associated injury } & $2[13.3 \%]$ & $2[13.3 \%]$ & 0.001 & 1.0 \\
\hline \multirow[t]{2}{*}{ Affected side } & Right & $12[80.0 \%]$ & $12[80.0 \%]$ & \multirow[t]{2}{*}{0.001} & \multirow[t]{2}{*}{1.0} \\
\hline & Left & $3[20.0 \%]$ & $3[20.0 \%]$ & & \\
\hline \multirow{3}{*}{$\begin{array}{l}\text { Type of } \\
\text { fracture }\end{array}$} & Transverse & $8[53.3 \%]$ & $8[53.3 \%]$ & \multirow[t]{3}{*}{1.07} & \multirow[t]{3}{*}{0.58} \\
\hline & Oblique & $7[46.7 \%]$ & $6[40.0 \%]$ & & \\
\hline & Intra-articular & $0[0.0 \%]$ & $1[6.7 \%]$ & & \\
\hline
\end{tabular}

Table [3]: Postoperative assessment among studied populations

\begin{tabular}{|c|c|c|c|c|c|}
\hline \multicolumn{2}{|c|}{ Variables } & Group 1 & Group 2 & Test & $P$ value \\
\hline \multicolumn{2}{|l|}{ TAM score } & $\begin{array}{c}241.67 \pm 24.54 \\
170-260\end{array}$ & $\begin{array}{c}237.67 \pm 22.42 \\
170-260\end{array}$ & 0.46 & 0.64 \\
\hline \multirow[t]{4}{*}{ TAM $\%$} & Excellent & $9[60.0 \%]$ & $8[53.3 \%]$ & \multirow[t]{4}{*}{1.45} & \multirow[t]{4}{*}{0.69} \\
\hline & Good & $4[26.7 \%]$ & $6[40.0 \%]$ & & \\
\hline & Fair & $1[6.7 \%]$ & $0[0.0 \%]$ & & \\
\hline & Poor & $1[6.7 \%]$ & $1[6.7 \%]$ & & \\
\hline \multicolumn{2}{|l|}{ Hand grip strength } & $\begin{array}{c}92.00 \pm 8.61 \\
70-100\end{array}$ & $\begin{array}{c}88.67 \pm 8.33 \\
70-100\end{array}$ & 1.07 & 0.29 \\
\hline \multicolumn{2}{|c|}{ Time to union [weeks] } & $\begin{array}{c}9.50 \pm 2.62 \\
6-14\end{array}$ & $\begin{array}{c}9.53 \pm 1.95 \\
6-14 \\
\end{array}$ & 0.039 & 0.96 \\
\hline \multirow[t]{4}{*}{ Complications } & No & $12[80.0 \%]$ & $10[66.7 \%]$ & \multirow[t]{4}{*}{2.84} & \multirow[t]{4}{*}{0.41} \\
\hline & Non-union & $1[6.7 \%]$ & $0[0.0 \%]$ & & \\
\hline & Pin site infection & $2[13.3 \%]$ & $4[26.7 \%]$ & & \\
\hline & Stiffness & $0[0.0 \%]$ & $1[6.7 \%]$ & & \\
\hline
\end{tabular}

\section{Cases presentation}

The first presented patient was a male patient, 26 years old, and he is a manual worker. He had a closed transverse fracture of $5^{\text {th }}$ metacarpal bone neck. Surgical intervention was done after 3 days of fracture, using intramedullary K-wires retrograde technique. No post-operative complications were noted. TAM score after 12 weeks was excellent [255] and hand grip strength was $90 \mathrm{~mm} \mathrm{Hg}$ [Figures 4-7].
The second presented patient is a male patient, 31 years and office worker. He had closed transverse fracture of $5^{\text {th }}$ metacarpal bone neck. Surgical intervention had been completed after 2 days of fracture, using transverse K-wires pinning technique. No post-operative complications were noted. TAM score after 12 weeks was good [240] and hand grip strength was $90 \mathrm{~mm} \mathrm{Hg}$ [Figures 811]. 


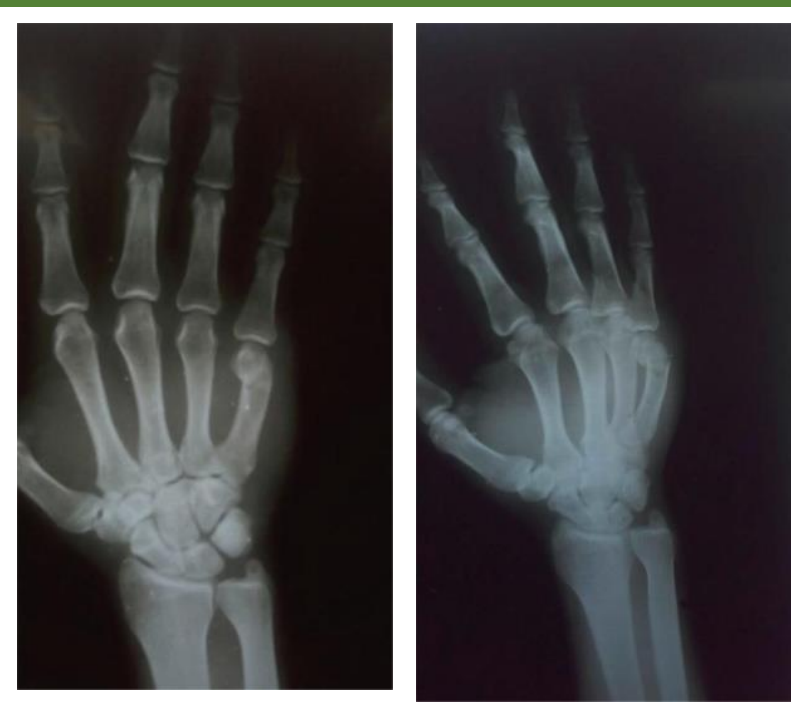

Figure [4]: Preoperative x-ray AP view [left] and oblique view [right]
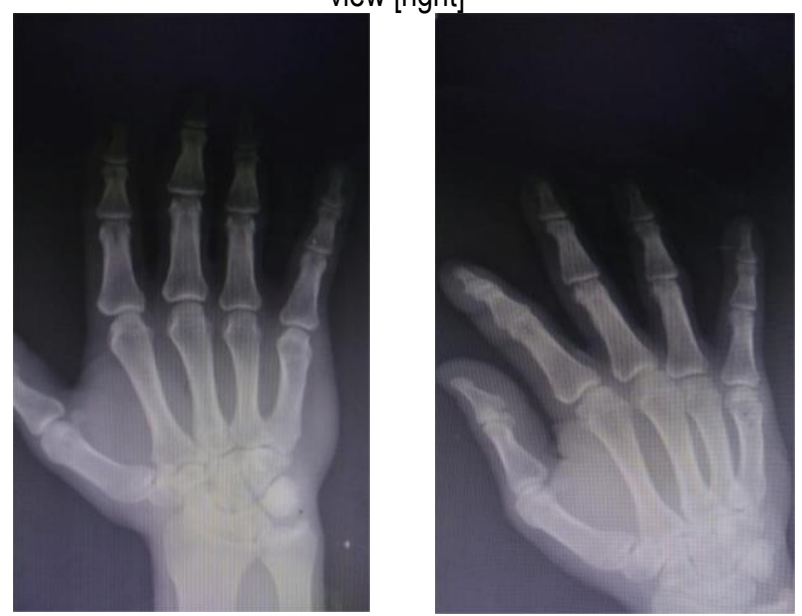

Figure [6]: Follow-up x-ray after 3 months AP view [left] and oblique view [right]

\section{DISUCSSION}

This study confirms that the functional and radiological results using both methods were excellent and they were statistically comparable. We believe that these results are attribute to relative simplicity of both techniques and its rapid performance without soft tissue dissection with no damage to the periosteal blood supply. This permits a predictable bony union. Previous studies reported comparable results. For example, Galanakis et al.[14] reported excellent functional and radiographic outcomes in a series of patients affected by unstable metacarpal fractures treated with percutaneous transverse fixation with $\mathrm{K}$-wires.

Winter et al.[15] in their short-term retrospective study, with a mean follow-up of 2.7



Figure [5]: Postoperative x-ray AP view [left] and oblique view [right]

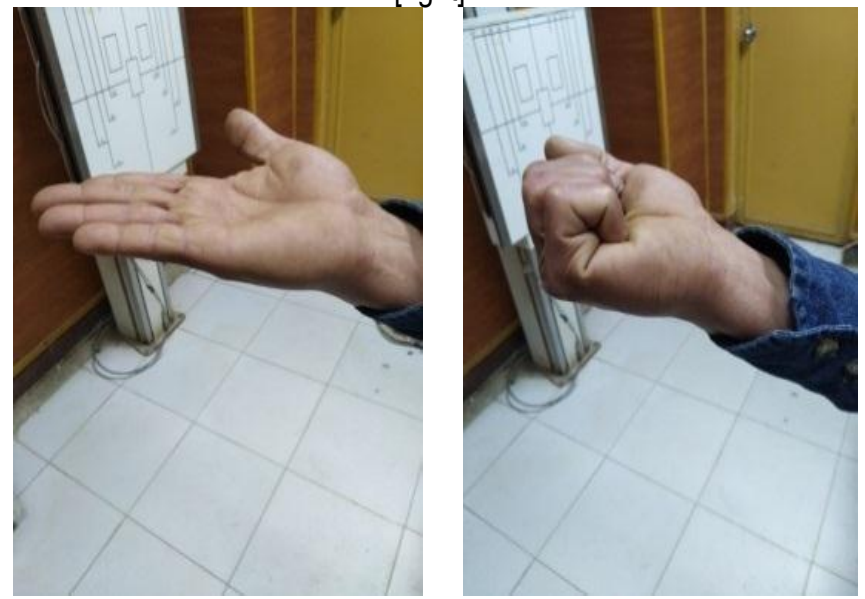

Figure [7]: Clinical follow-up after 3 months

months, reported that in the boxer's fracture, intramedullary pinning gave better functional outcomes than transverse pinning, although they concluded that intramedullary pinning is technically more demanding than transverse pinning and the surgeon has a more definite learning curve.

Fusetti et al.[16] reported that the main advantage of percutaneous transverse K-wire fixation or intramedullary K-wires in treating the Boxer's fracture is the avoidance of the complications occurring after open reduction and internal fixation, including infection, difficulties with fracture healing, stiffness due to extensive soft tissue dissection and later, fibrosis and extensor tendon adhesion, plate loosening or breakage and complex regional pain syndrome. 

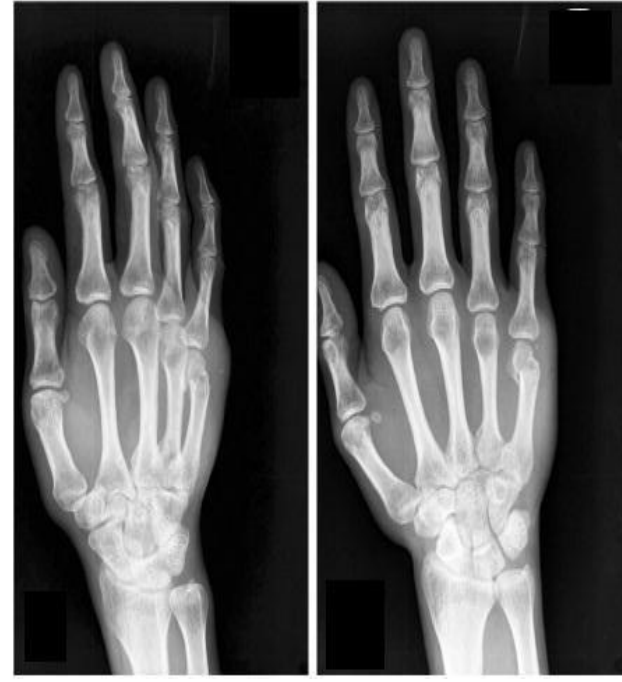

Figure [8]: Preoperative x-ray AP view [right] and oblique view [left]
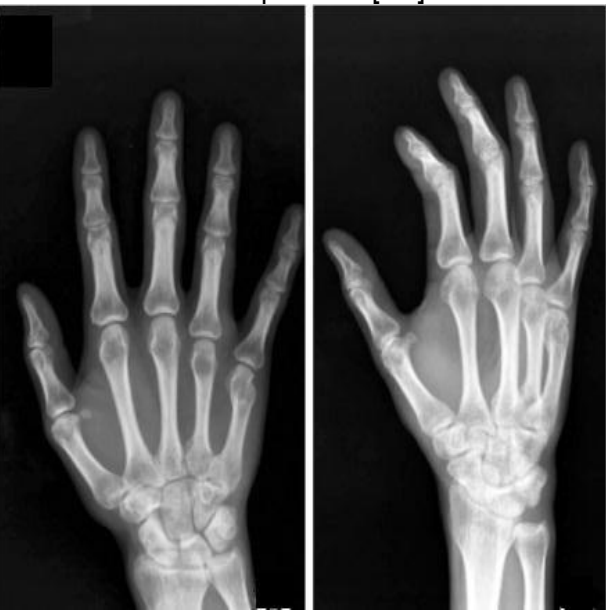

Figure [10]: Follow-up x-ray after 3 months AP view [left] and oblique view [right]

For objective postoperative assessment, we used total active movement [TAM] score, which revealed comparable results between both techniques. Similar results were reported by Wong et al.[17], who found that the mean TAM score was 250 for transverse group and 257 for intramedullary group in treatment of closed fractures of metacarpal of little finger. They included 59 patients and follow up was for 24 months.

Lee et al.[18] found that the mean of TAM score was 268 for intramedullary fixation of neck of fifth metacarpal fractures and was 266 for intramedullary fixation of shaft of fifth metacarpal fractures with no statistically difference after studying on 56 patients for 3 months.

Moon et al.[19] found that the mean of TAM score was 225 in intramedullary group and was 135 in percutaneous k-wire group. This result had been improved at late follow up to become 250 for intramedullary and 245 for percutaneous group. Although significant difference in early TAM was observed at 5 weeks, no statistically significance observed at $10^{\text {th }}$ operative week.

On the other side, Winter et al. ${ }^{[15]}$ reported that, the active range of motion of metacarpophalangeal joint was significantly different between the two procedures, with a better result in the intramedullary pinning group. This could be attributed to the fact that, they measured their score 12 months postoperatively, while the current one measured at 3 months postoperatively.

The time of union in the present work did not differ significantly between both groups [9.53 vs 9.5 weeks respectively]. However, one patient reported non union in the first group. Wong et al.,[17], also reported 
that the radiological union time for intramedullary and transverse group ranged from 6-16 weeks with mean 10 weeks for the two groups.

Winter et al. [15], reported that complete union in all fractures happened within 6 weeks.

On the other side, Moon et al.[19] reported that, the time of union in intramedullary nail group was 5.4 weeks and the time of union in percutaneous k-wires group was 5.2 weeks with no significant difference. [69]. Their results support the comparable outcome between both techniques. However, the duration of union is so short when compared to the present study and others in literature. We could not explain that, but we found another study with this short duration of union.

Khan et al.,[20] published that the follow up time was 12 weeks and the average union time was 5.4 weeks, at final plain x-ray examination never observed non-union. Possibly the difference could be attributed to the time of follow up and definition of union Han et al.[21] revealed that the radiological evaluation evidence of callus formation of all fracture was at 42 days on average range [32-54] days. Additionally, Mohammed et al.[22] found that all fractures proceeded to radiological bony union without rotational or sever angulation deformities and the wire was extracted in all patients at mean period 4.4 weeks.

In the present trial, we used hand grip to evaluate outcome and results revealed non significant difference between both groups. Winter et al.[15] found that grip strength was stronger after intramedullary pinning than after transverse pinning but the difference was not statistically significant where the mean for intramedullary was $92 \%$ of normal side and the mean for transverse group was $83 \%$.

Regarding incidence of complications in this study, the intramedullary group showed that 3 patients [20\%] had complications [2 for pin site infection who treated by broad spectrum antibiotics and frequent dressing and one nonunion]. In transverse group there were complications in 5 patients [33.3] [4 patient had pin site infection, treated by broad spectrum antibiotics, and one had stiffness in MPJ treated by physiotherapy for 4 weeks]. No significant difference was registered between both groups regarding complications.
Wong et al.[17], reported one patient in percutaneous group had stiffness of injured finger, while one patient in intramedullary group had k-wire migration which required early removal and treated with brace.

Winter et al. ${ }^{[15]}$ reported that there was no postoperative infection or digital neuropraxia in either group. One patient in the transverse group developed complex regional pain syndrome type 1 after having worn his splint for 4 weeks without coming for review.

Moon et al.[19] reported that, Patients in the intramedullary group reported no discomfort or swelling and less pain [mean VAS score, 9/100].

Boussakri el al.[23] found that there is only one patient presented with bad result overall of complicated reflex sympathetic dystrophy.

Finally, we could conclude that, both techniques of treatment of $5^{\text {th }}$ metacarpal neck fracture are valuable, easy and simple with minimal complications and excellent results.

One limiting step of the current work is the small number of included subjects, which hinders the globalization of data. Thus, future studies, preferably multicenter studies are encouraged.

\section{Financial and Non-Financial Relationships and Activities of Interest}

None.

\section{REFERENCES}

1. Cha SM, Shin HD. Antegrade Intramedullary Pinning in Subacute Fifth Metacarpal Neck Fracture After Failed Conservative Treatment: A Prospective Comparative Study with Acute Fracture. Ann Plast Surg. 2018;80 [4]: 347-352. [DOI: 10.1097/SAP.0000000000001265].

2. Taghinia AH, Talbot SG. Phalangeal and Metacarpal Fractures. Clin Plast Surg. 2019 Jul;46[3]:415-423. [DOI: 10.1016/j.cps.2019.02.011].

3. Cotterell IH, Richard MJ. Metacarpal and phalangeal fractures in athletes. Clin Sports Med. 2015 Jan; 34[1]: 69-98. [DOI: 10.1016/j.csm.2014.09.009].

4. Sletten NI, Nordsletten L, Husby T, Odegaard RA, Hellund JC, Kvernmo HD. Isolated, extra-articular neck and shaft fractures of the $4^{\text {th }}$ and $5^{\text {th }}$ metacarpals: a comparison of transverse and bouquet [intra- medullary] pinning in 67 patients. J Hand Surg Eur Vol. 2012; 37[5]:387-95. [DOI: 10.1177/ 1753193411431048.].

5. Jupiter JB. Fractures and Dislocation in the Hand. In: 
Browner BD, Levine AM, Trafton PG [eds]. Skeletal Trauma. 4theds. Philadelphia: Saunders Company; 2009. pp. 1221-331.

6. Franssen BB, Schuurman AH, Mink Molen A, Kon M. One century of Kirschner wires insertion techniques: a historical review. Acta Orthop Belg 2010; 76:1-6. [PMID: 20306956].

7. Foucher G. Bouquet II osteosynthesis in metacarpal neck fractures: a series of 66 patients. J Hand Surg Am. 1995 May; 20 [3 Pt 2]: S86-90. [DOI: 10.1016/s0363-5023 [95] 80176-6].

8. Berkman EF, Miles GH. Internal fixation of metacarpal fractures exclusive of the thumb. J Bone Joint Surg. 1943;25[4]:816-821. Quoted from: Foucher G. Bouquet II osteosynthesis in metacarpal neck fractures: a series of 66 patients. J Hand Surg Am. 1995 May;20[3 Pt 2]: S86-90. [DOI: 10.1016/s0363-5023[95]80176-6].

9. Nikkhah D, Berner JE, Pickford M. Intramedullary Screw Fixation of Metacarpal Fractures Results in Excellent Functional Outcomes: A Literature Review. Plast Reconstr Surg. 2020;145[1]:204e-205e. [DOI: 10.1097/ PRS.0000000000006340].

10. Yi JW, Yoo SL, Kim JK. Intramedullary Pinning for Displaced Fifth Metacarpal Neck Fractures: Closed Reduction and Fixation Using Either an Open Antegrade or Percutaneous Retrograde Technique. JBJS Essent Surg Tech. 2016 May 25; 6[2]: e21. [DOI: 10.2106/ JBJS.ST.16.00006].

11. Chiu YC, Tsai MT, Hsu CE, Hsu HC, Huang HL, Hsu JT. New fixation approach for transverse metacarpal neck fracture: a biomechanical study. J Orthop Surg Res. 2018;13[1]:183. [DOI: 10.1186/s13018-018-0890-2].

12. Kenney RJ, Hammert WC. Physical examination of the hand. J Hand Surg Am. 2014 Nov;39[11]:2324-34; quiz 2334. [DOI: 10.1016/j.jhsa.2014.04.026].

13. Martins JC, Aguiar LT, Lara EM, Teixeira-Salmela LF, Faria CD. Assessment of grip strength with the modified sphygmomanometer test: association between upper limb global strength and motor function. Braz J Phys Ther. 2015;19[6]:498-506. [DOI:10.1590/bjpt-rbf.2014. 0118].

14. Galanakis I, Aligizakis A, Katonis P, Papadokostakis G, Stergiopoulos K, Hadjipavlou A. Treatment of closed unstable metacarpal fractures using percutaneous transverse fixation with Kirschner wires. J Trauma 2003; 55: 509-13. [DOI: 10.1097/01.TA. 0000029368. 40479.A2].
15. Winter M, Balaguer T, Bessie re C, Carles M, Lebreton E. Surgical treatment of the boxer's fracture: transverse pinning versus intramedullary pinning. J Hand Surg Eur. 2007; 32:709-13. [DOI: 10.1016/J.JHSE.2007.07.011].

16. Fusetti C, Meyer H, Borisch N, Stern R, Santa DD, Papaloizos M. Complications of plate fixation in metacarpal fractures. J Trauma 2002; 52: 535-9. [DOI: 10.1097/00005373-200203000-00019].

17. Wong TC, Ip FK, Yeung SH. Comparison between percutaneous transverse fixation and intramedullary Kwires in treating closed fractures of the metacarpal neck of the little finger. J Hand Surg Br 2006; 31:61-5.

18. Lee SK, Kim KJ, Choy WS. Modified retrograde percutaneous intramedullary multiple kirschner wire fixation for treatment of unstable displaced metacarpal neck and shaft fractures. Eur J Orthop Surg Trumatol. 2013; 23: 535-43. [DOI: 10.1007/s00590-012-1036-6].

19. Moon SJ, Yang JW, Roh SY, Lee DC, Kim JS. Comparison between intramedullary nailing and percutaneous K-wire fixation for fractures in the distal third of the metacarpal bone. Arch Plast Surg 2014;41[6]:768-72. [DOI: 10.5999/aps.2014.41.6.768.].

20. Khan J, Shrestha SK, Pradhan NM, Acharya BK, Khanal $P$. Percutaneous $K$ wire fixation of fifth metacarpal neck fracture-new and simple technique. J Nepal Health Res Counc 2012; 10: 61-5. [PMID: 22929640]

21. Han SH, Rhee SY, Lee SC, Han SC, Cha YS Percutaneous retrograde intramedullary single wire fixation for metacarpal shaft fracture of the little finger. Eur J Orthop Surg Traumatol. 2013; 23: 883-7. [DOI: 10.1007/s00590-012-1112-y]

22. Mohammed R, Farook MZ, Newman K. Percutaneous elastic intramedullary nailing of metacarpal fractures: surgical technique and clinical results study. J Orthop Surg Res. 2011;6[1]:37.[DOI:10.1186/1749-799X-6-37].

23. Boussakri H, Elidrissi M, Azarkane M, Bensaad S, Bachiri M, Shimi M, Elibrahimi A, Elmrini A. Fractures of the neck of the fifth metacarpal bone, treated by percutaneous intramedullary nailing: surgical technique, radiological and clinical results study [28 cases]. Pan Afr Med J. 2014; 18: 187. [DOI: 10.11604/pamj. 2014. 18. 187.3347]. 